\title{
Alcohol consumption: An important epidemiological factor in COVID-19?
}

\author{
Abhimanyu Vasudeva ${ }^{1}$, Tejas K Patel $^{2}$
}

${ }^{1}$ Department of Physical Medicine and Rehabilitation, All India Institute of Medical Sciences, Gorakhpur Gorakhpur, Uttar Pradesh, India ${ }^{2}$ Department of Pharmacology, All India Institute of Medical Sciences, Gorakhpur, Gorakhpur, Uttar Pradesh, India

Alcohol-induced changes in pulmonary defense could increase the risk of acquiring SARS-Cov-2 infections and associated ARDS.
Alcohol gets absorbed via the bronchial circulation directly across the ciliated epithelium of the conducting airways. Vaporization during exhalation is followed by condensation as the air cools the vapors in the trachea eventually leading to a higher concentration of alcohol [8] which modifies airwayepithelium host defenses by altering cytokine release, barrier function, and ciliary function [9]. Alcohol also causes oxidative stress and alterations in alveolar macrophage functions [10]. This alteration in pulmonary defense could enhance the risk of acquiring SARSCov-2 infections. Moreover, ARDS is more likely in patients who have an injury to the lung by pathogens including viruses. A recent meta-analysis of 13 observational studies found an association between alcohol consumption and the risk of developing ARDS (1.89; 95\% CI $=1.45-2.48)$ among adults [11]. There appears to be a higher risk of acquiring COVID-19 related ARDS in chronic alcoholics (Figure 1). The World Health Organization (WHO) in its public information factsheet of COVID-19 states that heavy alcohol use increases the risk of ARDS, which is one of the complications of COVID-19. This factsheet was to caution the public regarding alcohol consumption and the fact that it is neither protective nor preventive against COVID-19, a common myth due to its important role in alcohol-based sanitizers for hand hygiene [12]. Alcohol consumption has been somewhat omitted from the perspective of risk factors for the severity of COVID-19 disease.
Alcohol consumption should be explored as a risk factor for COVID-19 disease and its complications. Changes in drinking habits may have profound implications for its prevention. 


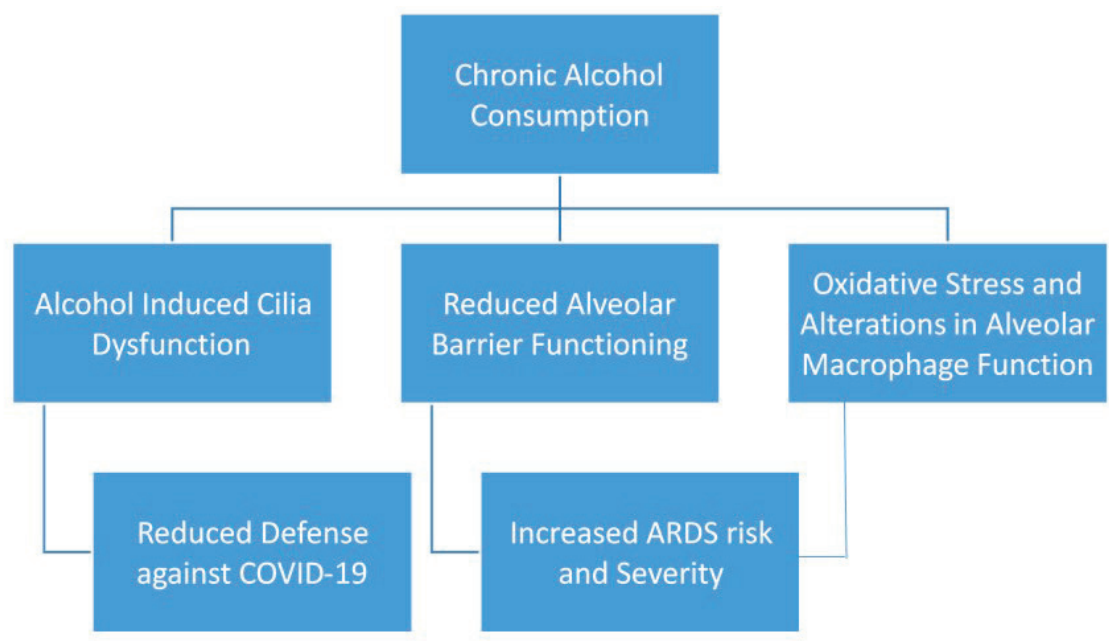

Figure 1. Deleterious effects of alcohol consumption on lung and its possible implications on COVID-19.

This hypothesis has profound implications as alcohol consumption is widespread throughout the world. Moreover, alcohol is hardly recognized as injurious to lung health as opposed to other organs such as the liver by the public at large. COVID-19 is an illness without a medication or a vaccine as of date, it would be in the public interest to highlight this association as a preventive measure. This virus may stay with us for a long time if not forever and changing drinking habits may go a long way in both reducing the spread of infection as well as reducing the chances of persons developing a serious illness. Conditions such as old age, hypertension, and diabetes, to name a few, have been identified as factors that can increase the risk of mortality due to this dreaded virus.

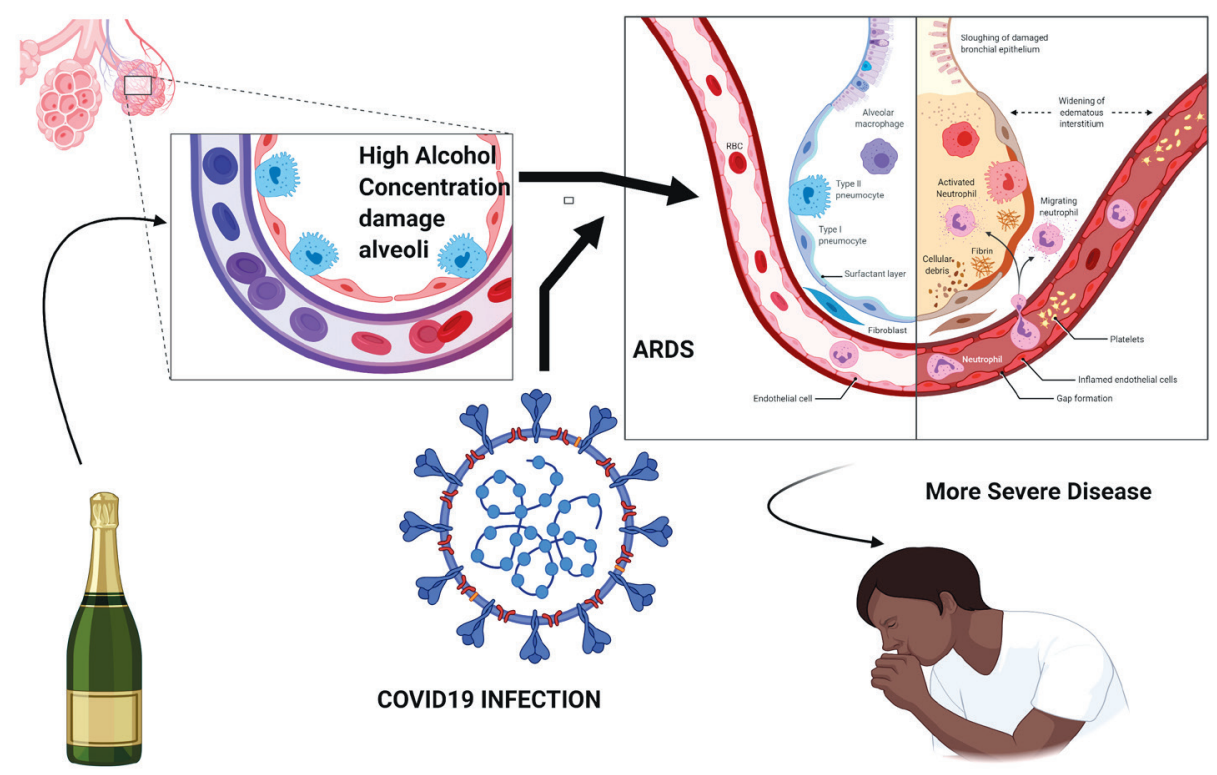

Photo: Created by Dr Samantak Sahu, Postgraduate trainee (MD), Department of Physical Medicine and Rehabilitation, All India Institute of Medical Sciences, New Delhi (used with permission).

\section{CONCLUSION}

We hypothesize that consumption of alcohol would lead to an increased risk of developing SARS-Cov-2 infections as well as severe illness. 
Acknowledgement: Authors want to thank Dr Samantak Sahu, Postgraduate trainee (MD), Department of Physical Medicine and Rehabilitation, All India Institute of Medical Sciences, New Delhi for his help in creating image to illustrate this viewpoint through BioRender.com.

Funding: The study is not funded.

Authorship contributions: AV conceived the idea. AV and TP searched the literature. AV drafted the manuscript and revised it with the inputs of TP.

Competing interests: The authors completed the ICMJE Unified Competing Interest form (available upon request from the corresponding author), and declare no conflicts of interest.

1 Huang C, Wang Y, Li X, Ren L, Zhao J, Hu Y, et al. Clinical features of patients infected with 2019 novel coronavirus in Wuhan, China. Lancet. 2020;395:497-506. Medline:31986264 doi:10.1016/S0140-6736(20)30183-5

2 Hu Y, Sun J, Dai Z, Deng H, Li X, Huanget Q, et al. Prevalence and severity of corona virus disease 2019 (COVID-19): A systematic review and meta-analysis. J Clin Virol. 2020;127:104371. Medline:32315817 doi:10.1016/j.jcv.2020.104371

3 Fu L, Wang B, Yuan T, Chen X, Ao Y, Fitzpatrick T, et al. Clinical characteristics of coronavirus disease 2019 (COVID-19) in China: A systematic review and meta-analysis. J Infect. 2020;80:656-65. Medline:32283155 doi:10.1016/j. jinf.2020.03.041

4 Zhu J, Ji P, Pang J, Zhong Z, Li H, He C, et al. Clinical characteristics of 3062 COVID-19 patients: A meta-analysis. J Med Virol. 2020. Online ahead of print. Medline:32293716 doi:10.1002/jmv.25884

5 Rodriguez-Morales AJ, Cardona-Ospina JA, Gutiérrez-Ocampo E, Villamizar-Peña R, Holguin-Rivera Y, Escalera-Antezana JP, et al. Clinical, laboratory and imaging features of COVID-19: A systematic review and meta-analysis. Travel Med Infect Dis. 2020;34:101623. Medline:32179124 doi:10.1016/j.tmaid.2020.101623

6 Li X, Ma X. Acute respiratory failure in COVID-19: is it "typical" ARDS? Crit Care. 2020;24:198. Medline:32375845 doi:10.1186/s13054-020-02911-9

7 Jin Y, Yang H, Ji W, Wu W, Chen S, Zhang W, et al. Virology, Epidemiology, Pathogenesis, and Control of COVID-19. Viruses. 2020;12:372. Medline:32230900 doi:10.3390/v12040372

8 George SC, Hlastala MP, Souders JE, Babb AL. Gas exchange in the airways. J Aerosol Med. 1996;9:25-33. Medline:10172721 doi:10.1089/jam.1996.9.25

9 Wyatt TA, Sisson JH. Chronic ethanol downregulates PKA activation and ciliary beating in bovine bronchial epithelial cells. Am J Physiol Lung Cell Mol Physiol. 2001;281:L575-81. Medline:11504683 doi:10.1152/ajplung.2001.281.3.L575

10 Liang Y, Harris FL, Brown LA. Alcohol induced mitochondrial oxidative stress and alveolar macrophage dysfunction. BioMed Res Int. 2014;2014:371593. Medline:24701574 doi:10.1155/2014/371593

11 Simou E, Leonardi-Bee J, Britton J. The Effect of Alcohol Consumption on the Risk of ARDS: A Systematic Review and Meta-Analysis. Chest. 2018;154:58-68. Medline:29288645 doi:10.1016/j.chest.2017.11.041

12 World Health Organization. Alcohol and COVID-19: what you need to know. 2020. Available: https://www.euro.who. int/_data/assets/pdf_file/0010/437608/Alcohol-and-COVID-19-what-you-need-to-know.pdf?ua=1. Accessed: 25 June 2020 .

\section{Correspondence to:}

Dr. Tejas K. Patel, M.D. Pharmacology

Associate Professor

Department of Pharmacology

All India Institute of Medical Sciences, Gorakhpur

Gorakhpur, Uttar Pradesh 273008, India

dr.tkp2006@yahoo.co.in 